\title{
Eliminating the Third Harmonic Effect for Six Phase Permanent Magnet Synchronous Generators in One Phase Open Mode
}

\author{
Jian Liu ${ }^{\dagger}$, Gui-jie Yang ${ }^{*}$, Yong Li ${ }^{*}$, Hong-wei Gao ${ }^{*}$, and Jian-yong Su ${ }^{*}$

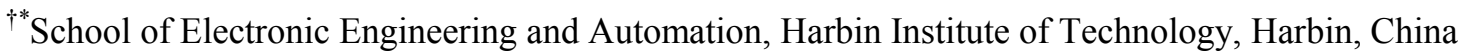

\begin{abstract}
To insure stable operation and eliminate twice torque ripple, a topology for a six phase permanent magnet synchronous generator (SP-PMSG) with a neutral point connected together was analyzed in this paper. By adopting an extended transformation matrix, the mathematic model of the space vector control was established. The voltage and torque equations were deduced while considering the third harmonic flux and inductance. In addition, the suppression third harmonic method and the closed loop control strategy were proposed. A comparison analysis indicates that the cooper loss minimum method and the current magnitude minimum method can meet different application requirements. The voltage compensation amount for each of the methods was deduced which also takes into account the third harmonic effect. A simulation and experimental result comparison validates the consistency through theoretical derivation. It can be seen that all of the two control strategies can meet the requirements of post-fault.
\end{abstract}

Key words: Current magnitude minimum, Fault tolerant operation, Six phase permanent magnet synchronous generator, Stator cooper loss minimum

\section{INTRODUCTION}

The multi-phase PMSM has attracted more comprehensive attention in recently years [1]-[3]. In addition to the advantages such as small size, light weight, high power density and efficiency when compared with conventional three phase machines, they also have advantages such as high power output with low voltage and fault tolerant [4]-[7]. By increasing the number of stator winding phases, a SP-PMSG can reduces the phase current dramatically. At the same time, the zero sequence circulation current was thoroughly avoided such as in a parallel converter applied to wind energy conversion systems. Filter design is difficult in the high current application. By connecting the neutral point with different topology, it can realize mid-voltage grid connection by DC-bus series [8], or it can enhance the system stability and meet the requirements of the filter by a parallel topology.

In multi-phase machines, when faults occur in one or more of the phases, the machine can still operate with the healthy

Manuscript received Jan. 31, 2013; revised Oct. 11, 2013.

Recommended for publication by Associate Editor Sanjeet K. Dwivedi. ${ }^{\dagger}$ Corresponding Author: liujian hit@163.com

Tel: +86-451-86415240, Harbin Institute of Technology

* School of Electronic Engineering and Automation, Harbin Institute of Technology, China phases [9]-[12]. In order to solve the problem of fault tolerance, one of the related control techniques for it is ohmic loss minimum [13],[14], which can limit the loss in fault mode. Nevertheless, the maximum torque output of the machine was also limited. Another technique is one that limits the maximum magnitude of stator current [15]. It can make each phase current have the same or nearly the same magnitude, and it caused the ohmic loss to increase. Minimizing the inverter inactive power transfer was also introduced [16]. In practice, fault tolerant control is an optimizing process of the stator current. The stator phase currents are optimized to keep the rotating MMF undisturbed under fault mode, and to eliminate the torque ripple. Compared with the third harmonic, the effects of other low harmonic are slight. Many studies have focused on inhibiting the twice ripple of the torque which caused by the third harmonic. To inhibit the torque ripple in the fault mode of a five phase motor, the third harmonic was eliminated by using the instantaneous power balance method [17]. However, it cannot reflect the coupling relationship of the d-q subspace which involves the electromechanical energy conversion and harmonic subspace which involves the harmonic losses, and each subspace cannot decouple completely [18]. A third harmonic injection method to reduce the output torque ripples of a five phase PMSM under one 
phase open faults is reported in [19]. This method caused an increase in the stator ohmic loss and it can lead to a deterioration of the torque ripples. By applying the extended transformation matrix for the stator current, the twice and fourth torque ripples were separated, and it can decouple the $\mathrm{d}-\mathrm{q}$ subspace and harmonic subspace and adopt the closed loop control separately [20]. Based on the proposed theory, this paper presents the decoupling matrix for the stator current in the fault mode. By applying the matrix, the ohmic loss calculation expression and the decoupled fundamental voltage and third harmonic voltage expression were deduced. The proposed method was applied to the ohmic loss minimum and the stator current magnitude minimum strategies, in order to inhibit the torque ripples. The compensation voltage for both of the strategies in the close loop control were analyzed in depth. All of these proposed methods were applied to a SP-PMSG which was specially adapted from an induction motor with 36 slots.

This paper is organized as follows. The mathematical model and the extended transformation matrix for the one phase open mode were proposed in Section 2. The optimization current methods using the ohmic loss minimum and the stator current magnitude minimum strategies were presented in Section 3. The compensation method in the closed loop control was illustrated in Section 4 to eliminate the effects caused by the third harmonic. Simulations and experiments were carried out to validate the proposed method and are shown in Section 5 . Some meaningful conclusions are given in Section 6.

\section{MATHEMATICAL MODEL OF A SP-PMSM IN THE FAULT MODE}

\section{A. SP-PMSG Mathematical Model in the Fault Mode}

Fig. 1 shows the topology of a SP-PMSM connected to a voltage source converter with a $\mathrm{Z}$ phase opening. In this figure, $\boldsymbol{C}_{d c}$ represent the capacity of the DC-bus, $\boldsymbol{V}_{d c}$ is the voltage of the DC-bus, A-B-C and X-Y-Z represent the two sets of three phase windings, where $\mathrm{X}-\mathrm{Y}-\mathrm{Z}$ shift 30 degrees from A-B-C, and the two sets winding's neutral points were connected together.

In the normal state, the flux distributes the air-gap evenly, the current of each phase is also balanced, and stator current can be expressed as (1).

$$
\boldsymbol{i}_{\mathrm{S}}=I_{m 1} \sin \left(\omega_{e} t-\gamma_{n}\right)
$$

where, $\boldsymbol{i}_{\mathrm{s}}$ denotes the stator current vector, $I_{\mathrm{m} 1}$ denotes the magnitude of the fundamental, $\omega_{\mathrm{e}}$ is the electrical angular velocity, and $\gamma_{\mathrm{n}}$ is the original angle vector, shown as (2), where $n$ denote A, B, C, X, Y, Z.

$$
\gamma_{n}=\left[0 \frac{2 \pi}{3}-\frac{2 \pi}{3} \frac{\pi}{6} \frac{5 \pi}{6}\right]^{\mathrm{T}}
$$

According to the $\mathrm{N}$ phase stationary transformation theory described in [21], the six phase motor discussed in this paper is

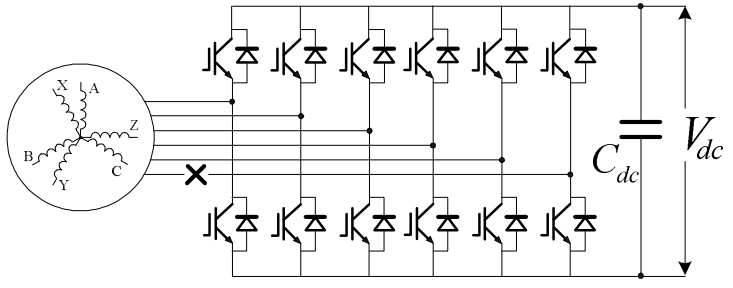

(a)

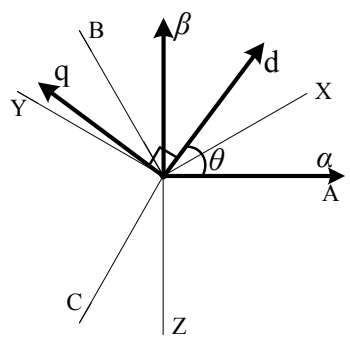

(b)

Fig. 1. Topology structure with $\mathrm{Z}$ phase opening and reference frame a) topology of the referred SP-PMSG, b) stationary frame to d-q reference frame.

a semi-twelve phase motor. According to Fig. 1 b) the $\alpha-\beta$ coordinates and $\mathrm{d}-\mathrm{q}$ frame, it can gain a transformation matrix that is the so-called $\boldsymbol{T}_{6 \mathrm{~s}}$. Remove the row corresponding to the open phase, the transformation matrix for open phase called $\boldsymbol{T}_{5 \mathrm{~s}}$ it then consist of the five vectors that are orthogonal each other. As (3) shows, the original matrix was not satisfying the orthogonal condition. By extending the transformation matrix to fit (3), the matrix was split into the $\alpha-\beta$ subspace and the $z 1-z 3$ subspace. As (4) shows, the former represents the electromechanical energy conversion subspace and the latter contributes to the losses. For a motor with non-isolated neutral point, the sum of stator current is zero. As a result, all of the elements of $z 3$ subspace must be set to 1 . In order to make all of the vectors orthogonal, all of the elements of $\beta$ subspace can subtract 0.2 . The extended transformation matrix elements are shown in (5) after adjustment.

$$
\begin{aligned}
& \boldsymbol{\alpha}^{\mathrm{T}} \cdot \boldsymbol{\beta}=\boldsymbol{\alpha}^{\mathrm{T}} \cdot \boldsymbol{z} \mathbf{1}=\boldsymbol{\alpha}^{\mathrm{T}} \cdot \boldsymbol{z} \mathbf{2}=\boldsymbol{\alpha}^{\mathrm{T}} \cdot \boldsymbol{z} \mathbf{3}=0 \\
& \boldsymbol{\beta}^{\mathrm{T}} \cdot \boldsymbol{z} \mathbf{1}=\boldsymbol{\beta}^{\mathrm{T}} \cdot \boldsymbol{z} \mathbf{2}=\boldsymbol{\beta}^{\mathrm{T}} \cdot \boldsymbol{z} \mathbf{3}=0 \\
& z 1^{\mathrm{T}} \cdot \boldsymbol{z} 2=z 1^{\mathrm{T}} \cdot z 3=z 2^{\mathrm{T}} \cdot z 3=0 \\
& T_{5 s}=\left[\begin{array}{lllll}
\boldsymbol{\alpha} & \boldsymbol{\beta} & \boldsymbol{z} 1 & \boldsymbol{z} 2 & \boldsymbol{z} 3
\end{array}\right]^{\mathrm{T}} \\
& \boldsymbol{T}_{5 \mathrm{~s}}=\frac{1}{3}\left[\begin{array}{ccccc}
1 & -\frac{1}{2} & -\frac{1}{2} & \frac{\sqrt{3}}{2} & -\frac{\sqrt{3}}{2} \\
-\frac{1}{5} & \frac{\sqrt{3}}{2}-\frac{1}{5} & -\frac{\sqrt{3}}{2}-\frac{1}{5} & \frac{1}{2}-\frac{1}{5} & \frac{1}{2}-\frac{1}{5} \\
1 & -\frac{1}{2} & -\frac{1}{2} & -\frac{\sqrt{3}}{2} & \frac{\sqrt{3}}{2} \\
-\frac{2}{3} & -\frac{2}{3}-\frac{\sqrt{3}}{3} & -\frac{2}{3}+\frac{\sqrt{3}}{3} & 1 & 1 \\
1 & 1 & 1 & 1 & 1
\end{array}\right]
\end{aligned}
$$


The rotational transformation matrix can be written as (6).

$$
\boldsymbol{P}(\theta)=\left[\begin{array}{ccc}
\cos \theta & \sin \theta & \mathbf{0}_{1 \times 3} \\
-\sin \theta & \cos \theta & \mathbf{0}_{1 \times 3} \\
\mathbf{0}_{3 \times 1} & \mathbf{0}_{3 \times 1} & \boldsymbol{I}_{3 \times 3}
\end{array}\right]
$$

where $\theta=\omega_{e} t, \omega_{e}$ is the electrical angular speed.

By applying the stationary and rotational transformation matrix to (1), the decoupled current can be gained.

$$
\boldsymbol{i}_{\mathrm{dqz}}^{\mathrm{T}}=\boldsymbol{T}(\theta) \boldsymbol{i}_{S}^{\mathrm{T}}
$$

where $\boldsymbol{T}(\theta)=\boldsymbol{P}(\theta) \cdot \boldsymbol{T}_{5 \mathrm{~s}}, \quad \boldsymbol{i}_{\mathrm{dqz}}^{\mathrm{T}}{ }^{\mathrm{T}}$ consists of $i_{\mathrm{d}}-i_{\mathrm{q}}$ and $i_{\mathrm{z} 1}-i_{\mathrm{z} 3}$, the $i_{\mathrm{d}}-i_{\mathrm{q}}$ involved in the energy conversion which the MMF produced by the healthy phase is equal to the MMF produced by the two equivalent windings on the $d-q$ axes or the $\alpha-\beta$ axes.

The stator voltage in the $\mathrm{d}-\mathrm{q}$ frame can be written as traditional three phase motor as follows:

$$
\begin{aligned}
\boldsymbol{u}_{\mathrm{dqz}} & =R_{s} \boldsymbol{i}_{\mathrm{dqz}}+\boldsymbol{A}_{1}(\theta) \boldsymbol{L}_{\mathrm{dqz}} \frac{d \boldsymbol{i}_{\mathrm{dqz}}}{d t} \\
& +\omega \boldsymbol{A}_{1}(\theta)\left[\begin{array}{ccc}
0 & -L_{\mathrm{qs}} & \mathbf{0}_{1 \times 3} \\
L_{\mathrm{ds}} & 0 & \mathbf{0}_{1 \times 3} \\
\mathbf{0}_{3 \times 1} & \mathbf{0}_{3 \times 1} & \mathbf{0}_{3 \times 3}
\end{array}\right] \boldsymbol{i}_{\mathrm{dqz}}+\omega \boldsymbol{B}_{1}(\theta)
\end{aligned}
$$

where $R_{\mathrm{s}}$ is the stator resistance, $\boldsymbol{L}_{\mathrm{dqz}}$ is the inductance in the d-q frame, $\boldsymbol{A}_{1}(\theta)$ is the coefficient matrix corresponding to the fundamental voltage, and $\boldsymbol{B}_{1}(\theta)$ is the fundamental flux in the rotational frame as follows:

$$
\begin{aligned}
& \boldsymbol{A}_{1}(\theta)=\left[\begin{array}{cccc}
0.8+0.2 \cos 2 \theta & -0.2 \sin 2 \theta & \mathbf{0}_{1 \times 2} & 0.12 \sin \theta \\
-0.2 \sin 2 \theta & 0.8+0.2 \cos 2 \theta & \mathbf{0}_{1 \times 2} & 0.12 \cos \theta \\
\mathbf{0}_{2 \times 1} & \mathbf{0}_{2 \times 1} & \mathbf{0}_{2 \times 2} & \mathbf{0}_{2 \times 1} \\
0.33 \sin \theta & 0.33 \sin \theta & \mathbf{0}_{1 \times 2} & 0.0667
\end{array}\right] \\
& \boldsymbol{B}_{1}(\theta)=\psi_{\mathrm{m} 1}\left[\begin{array}{c}
-0.2 \sin 2 \theta \\
0.8-0.2 \cos 2 \theta \\
0 \\
0 \\
0.333 \sin \theta
\end{array}\right]
\end{aligned}
$$

If only the third harmonic inductance and the flux are considered, the third harmonic voltage can be expressed as follows:

$$
\begin{aligned}
\boldsymbol{u}_{3 \mathrm{dqz}}= & \boldsymbol{T}^{-1}(\theta) \frac{d \boldsymbol{\psi}_{3}}{d t}=L_{m 3} \boldsymbol{A}_{3}(\theta) \frac{d \boldsymbol{i}_{d q z}}{d t} \\
& +\omega L_{m 3} \boldsymbol{B}_{3}(\theta) \boldsymbol{i}_{d q z}+\omega \psi_{\mathrm{fd}} \boldsymbol{C}_{3}(\theta)
\end{aligned}
$$

where $\psi_{3}=\boldsymbol{L}_{m 3} \frac{d \boldsymbol{i}_{d q z}}{d t}+\psi_{m 3}$ is the third harmonic flux, $\boldsymbol{A}_{3}(\theta)$ and $\boldsymbol{B}_{3}(\theta)$ are the coefficient matrixes which relate to the inductance after the rotational coordinate transformation, $\boldsymbol{A}_{3}(\theta)$ show at the top of this page. $\boldsymbol{C}_{3}(\theta)$ can be gained by applying $\boldsymbol{T}(\theta)$ to the third harmonic flux.

$$
A_{3}(\theta)=\left[\begin{array}{ccccc}
0.2-0.2 \cos 2 \theta & 0.2 \sin 2 \theta & 0 & 0.6 \sin \theta & -0.12 \sin \theta \\
0.2 \sin 2 \theta & 0.2+0.2 \cos 2 \theta & 0 & 0.6 \cos \theta & -0.12 \cos \theta \\
0 & 0 & 0 & 0 & 0 \\
1.33 \sin \theta & 1.33 \cos \theta & 0 & 2 & -0.4 \\
0.33 \sin \theta & -0.33 \cos \theta & 0 & -0.5 & 2.6
\end{array}\right]
$$

$$
\begin{aligned}
& \boldsymbol{B}_{3}(\theta)=\left[\begin{array}{ccc}
0.2 \sin 2 \theta & -0.2(1-\cos 2 \theta) & \mathbf{0}_{1 \times 3} \\
0.2(1+\cos 2 \theta) & -0.2 \sin 2 \theta & \mathbf{0}_{1 \times 3} \\
0 & 0 & \mathbf{0}_{1 \times 3} \\
1.33 \cos \theta & -1.33 \sin \theta & \mathbf{0}_{1 \times 3} \\
-0.33 \sin \theta & 0.33 \sin \theta & \mathbf{0}_{1 \times 3}
\end{array}\right] \\
& \boldsymbol{C}_{3}(\theta)=\psi_{\mathrm{m} 3}\left[\begin{array}{c}
0.3(\cos 2 \theta-\cos 4 \theta-\sin 2 \theta+\sin 4 \theta) \\
0.3(-\cos 2 \theta-\cos 4 \theta+\sin 2 \theta+\sin 4 \theta) \\
0 \\
2(\cos 3 \theta-\sin 3 \theta) \\
2 \cos 3 \theta-3 \sin 3 \theta
\end{array}\right]
\end{aligned}
$$

For equation (8), the fundamental was taken into account only, after applying $\boldsymbol{T}(\theta)$. It can be seen in $\boldsymbol{A}(\theta)$. It includes twice the ripples between the d-q axes which is not decoupled completely. Therefore, it is possible to multiply $\boldsymbol{P}(\theta)$ only for the $\mathrm{d}$-q frame to gain a completely decoupled model. $\boldsymbol{P}(\theta)$ is shown in (10), and this is not for the third harmonic voltage. It can be an independent variable to control.

$$
\boldsymbol{P}(\theta)=\left[\begin{array}{cc}
0.8+0.2 \cos 2 \theta & -0.2 \sin 2 \theta \\
-0.2 \sin 2 \theta & 0.8+0.2 \cos 2 \theta
\end{array}\right]^{-1}
$$

The decoupled voltage in the $d-q$ frame is the sum of the fundamental and the third harmonic voltage.

The inductance matrix is show in (11). It considers the third harmonic inductance effect. The flux induced by the magnets shows in (12), consists of fundamental and third harmonic flux.

$$
\begin{aligned}
& \boldsymbol{L}_{\mathrm{S}}=L_{l s} \boldsymbol{I}_{4 \times 4}+\boldsymbol{L}_{m 1}+\boldsymbol{L}_{m 3}=L_{l s} \boldsymbol{I}_{4 \times 4} \\
& +L_{m 1}\left[\begin{array}{ccccc}
1 & -\frac{1}{2} & -\frac{1}{2} & \frac{\sqrt{3}}{2} & -\frac{\sqrt{3}}{2} \\
-\frac{1}{2} & 1 & -\frac{1}{2} & 0 & \frac{\sqrt{3}}{2} \\
-\frac{1}{2} & -\frac{1}{2} & 1 & -\frac{\sqrt{3}}{2} & 0 \\
\frac{\sqrt{3}}{2} & 0 & -\frac{\sqrt{3}}{2} & 1 & -\frac{1}{2} \\
-\frac{\sqrt{3}}{2} & \frac{\sqrt{3}}{2} & 0 & -\frac{1}{2} & 1
\end{array}\right] \\
& +L_{m 3}\left[\begin{array}{lllll}
1 & 1 & 1 & 0 & 0 \\
1 & 1 & 1 & 0 & 0 \\
1 & 1 & 1 & 0 & 0 \\
0 & 0 & 0 & 1 & 1 \\
0 & 0 & 0 & 1 & 1
\end{array}\right] \\
& \psi_{m}=\psi_{m 1}+\psi_{m 3}=\psi_{m 1}\left[\begin{array}{c}
\cos \theta \\
\cos \left(\theta-\frac{2 \pi}{3}\right) \\
\cos \left(\theta+\frac{2 \pi}{3}\right) \\
\cos \left(\theta-\frac{\pi}{6}\right) \\
\cos \left(\theta-\frac{5 \pi}{6}\right)
\end{array}\right]+\psi_{m 3}\left[\begin{array}{c}
\cos 3 \theta \\
\cos 3 \theta \\
\cos 3 \theta \\
\sin 3 \theta \\
\sin 3 \theta
\end{array}\right]
\end{aligned}
$$




\section{B. Torque and Power Equation in Fault Mode}

It is well known that torque can be calculated by partial differentiation of the co-energy that is stored in the stator inductance and the permanent magnet, as shown in (13).

$$
\begin{aligned}
T_{e} & =\frac{\partial W_{c}}{\partial \theta_{m}}=p_{\mathrm{n}}\left(\frac{1}{2} \boldsymbol{i}_{\mathrm{S}}^{\mathrm{T}} \frac{\partial \boldsymbol{L}_{s}}{\partial \theta} \boldsymbol{i}_{\mathrm{s}}+\boldsymbol{i}_{\mathrm{s}}^{\mathrm{T}} \frac{\partial \psi_{m}}{\partial \theta}\right) \\
& =p_{n}\left[\left(\boldsymbol{T}^{-1}(\theta) \boldsymbol{I}_{d q z}\right)^{\mathrm{T}} \boldsymbol{T}^{-1}(\theta) \frac{\partial \psi_{d q}}{\partial \theta}\right]
\end{aligned}
$$

where $\boldsymbol{W}_{c}$ is the co-energy of the motor, $\theta_{m}$ is the mechanical angular speed, $p$ is the pole pairs, and the first part of (13) equals zero for the surface mounted permanent magnet motor. It will not induce the torque ripple in the fault mode, and only the flux induced by the magnet was considered. By applying the rotational transformation matrix, and substituting (12) into (13), the torque can be gained as shown in (14). It can be seen that the torque is more complicated than the fundamental. Because it was taken into account the twice, third, fourth harmonics components were involved in the torque.

$$
\begin{aligned}
T_{e} & =3 p_{n}\left(\psi_{m 1} i_{q 1}+\frac{1}{5} \psi_{m 1} i_{z 3} \cos \theta\right) \\
& +\frac{3}{2} p_{n} \psi_{m 3}\left[i_{d 1}(\cos 2 \theta-\cos 4 \theta-\sin 2 \theta+\sin 4 \theta)\right. \\
& +i_{q 1}(\cos 2 \theta+\cos 4 \theta+\sin 2 \theta+\sin 4 \theta) \\
& \left.+i_{z 2}(3 \cos 3 \theta+3 \sin 3 \theta)+i_{z 3}\left(\frac{12}{5} \cos 3 \theta+\frac{18}{5} \sin 3 \theta\right)\right]
\end{aligned}
$$

According to the instantaneous theory, the power can be expressed as follows:

$$
\begin{aligned}
& S=\sum_{i=1}^{5} u_{i} \cdot i_{i} \\
& P=P_{a c t}+P_{z} \\
& Q=u_{\beta} \cdot i_{\alpha}-u_{\alpha} \cdot i_{\beta}
\end{aligned}
$$

where $S$ is the apparent power, $P$ is the active power, which contains $P_{a c t}$ and $P_{z}, P_{a c t}=P_{s w}+U_{d c} \cdot I_{d c}, \quad P_{s w}$ is the switch loss, $P_{z}=\sum_{i=1}^{5} R \cdot i_{i}+u_{z 1} \cdot i_{z 1}+u_{z 2} \cdot i_{z 2}+u_{z 3} \cdot i_{z 3}$, and $Q$ is the reactive power.

\section{SP-PMSG FAULT TOLERANT CONTROL IN THE ONE PHASE OPEN MODE}

\section{A. Stator Ohmic Loss Minimum Control (M1)}

In the one phase open mode, the power devices of the converter can stand the fault current under a light load because the phase number is increased. Therefore, the M1 method fits this occasion. This control strategy can lead to lower loss and gain a higher power output if the rated current of the converter is not limited.

The ohmic loss of the SP-PMSG can be expressed as follows. As can be seen in (18), in order to get lower losses, $i_{\mathrm{d}}$ can be set to zero. In addition, (18) can be simplified as (19).

$$
\begin{aligned}
P= & \boldsymbol{i}_{S}{ }^{T} \boldsymbol{i}_{S} R_{S}=\left(T^{-1}(\theta) \boldsymbol{i}_{\mathrm{dqz}}\right)^{\mathrm{T}}\left(T^{-1}(\theta) \boldsymbol{i}_{\mathrm{dqz}}\right) R_{s} \\
= & \frac{4}{3} R_{S}\left[\left(I_{d}^{2}+I_{q}^{2}\right)+\frac{1}{3}\left(I_{q}^{2}-I_{d}^{2}\right) \cos 2 \theta\right. \\
& \left.+\frac{2}{3} I_{d} I_{q} \sin 2 \theta+I_{z 1}^{2}+0.75 I_{z 2}^{2}+0.6 I_{z 3}^{2}\right] \\
P= & R_{S}\left(\frac{4}{3} I_{q}^{2}+\frac{1}{3} I_{q}^{2} \cos 2 \theta+I_{z 1}^{2}+0.75 I_{z 2}^{2}+0.6 I_{z 3}^{2}\right)
\end{aligned}
$$

The phase currents can be written in a complex form as shown in (20).

$$
i_{n}=X_{\mathrm{n}} I_{\mathrm{m}} \cos \theta_{\mathrm{i}}+Y_{\mathrm{n}} I_{\mathrm{m}} \sin \theta_{i}=X_{\mathrm{n}} I_{\alpha}+Y_{\mathrm{n}} I_{\beta}
$$

where $n$ represents $\mathrm{A}, \mathrm{B}, \mathrm{C}, \mathrm{X}, \mathrm{Y}, \mathrm{Z}$, and $X_{\mathrm{n}}$ and $Y_{\mathrm{n}}$ are unknown variables. For smooth torque production, torque ripples equal to zero are preferred. Therefore, the MMF is balance under normal or fault operations. $X_{\mathrm{n}}$ and $Y_{\mathrm{n}}$ satisfy the conditions as shown in (21) [9]:

$$
\left\{\begin{array}{l}
X_{\mathrm{A}}+\sqrt{3} X_{\mathrm{X}} / 2-0.5 X_{\mathrm{B}}-\sqrt{3} X_{\mathrm{Y}} / 2-0.5 X_{\mathrm{C}}=3 \\
Y_{\mathrm{A}}+\sqrt{3} Y_{\mathrm{X}} / 2-0.5 Y_{\mathrm{B}}-\sqrt{3} Y_{\mathrm{Y}} / 2-0.5 Y_{\mathrm{C}}=0 \\
0.5 X_{\mathrm{X}}+\sqrt{3} X_{\mathrm{B}} / 2+0.5 X_{\mathrm{Y}}-\sqrt{3} X_{\mathrm{C}} / 2=0 \\
0.5 Y_{\mathrm{X}}+\sqrt{3} Y_{\mathrm{B}} / 2+0.5 Y_{\mathrm{Y}}-\sqrt{3} Y_{\mathrm{C}} / 2=3
\end{array}\right.
$$

For the topology considered in this paper, the neutral point was connected together, so the real and imaginary parts also satisfy the condition shown in (22).

$$
\left\{\begin{array}{l}
X_{\mathrm{A}}+X_{\mathrm{B}}+X_{\mathrm{C}}+X_{\mathrm{X}}+X_{\mathrm{Y}}=0 \\
Y_{\mathrm{A}}+Y_{\mathrm{B}}+Y_{\mathrm{C}}+Y_{\mathrm{X}}+Y_{\mathrm{Y}}=0
\end{array}\right.
$$

To gain the optimal current, Lagrangian function can be used to calculate the real and imaginary parts of the current value offline. For loss minimum consideration, the sum square of the current can be an objective function, as can be seen in (19). This means that the objective function can be written as (23). The objective function satisfies (21) and (22). As a result, the extreme value of the Lagrangian function is the solution of the optimal current.

$$
f\left(X_{i}, Y_{i}\right)=\sum_{i=1}^{5}\left(X_{i}^{2}+Y_{i}^{2}\right)
$$

The solution is shown in (24), and the initial phase angle is in radians. It can be seen that $\boldsymbol{i}_{\mathrm{c}}$ reaches 1.846 times than normal operation. It is worth noting that the maximum of the stator current is limited by the converter rated current. Therefore, the generator can gain higher efficiency under the M1 strategy. However, if the current approaches the rated current, the over current can lead to converter fault protection.

$$
\left\{\begin{array}{l}
i_{A}=1.054 I_{m} \sin \left(\theta_{i}+0.32\right) \\
i_{B}=1.217 I_{m} \sin (\theta-1.993) \\
i_{C}=1.846 I_{m} \sin \left(\theta_{i}+1.845\right) \\
i_{X}=I_{m} \sin \left(\theta_{i}-\frac{\pi}{6}\right) \\
i_{Y}=I_{m} \sin \left(\theta_{i}-\frac{5 \pi}{6}\right)
\end{array}\right.
$$

\section{B. Stator Current Magnitude Minimum Control (M2)}


To overcome a phase current that is much higher than others, the M2 strategy was proposed. It is an optimization process to obtain the minimum current magnitude, by optimizing the z1-z3 harmonic subspace currents. The solution is the minimum of the optimal results. Some optimization functions can be readily used for this optimization problem, such as the fmincon and fminmax provided by Matlab. The optimization function is shown in (25).

$$
f\left(X_{i}, Y_{i}\right)=\operatorname{fun}\left(X_{A}^{2}+Y_{A}^{2}, X_{B}^{2}+Y_{B}^{2}, X_{C}^{2}+Y_{C}^{2}, X_{X}^{2}+Y_{X}^{2}, X_{Y}^{2}+Y_{Y}^{2}\right)
$$

where (21) and (22) can be constraints for the optimal function, and the range of $X_{\mathrm{i}}$ and $Y_{\mathrm{i}}$ are not limited between 0 to 1 . The initial value should be set for optimization. After several attempts at optimization, an effective solution was determined, as shown in (23). The initial phase angle is in radians.

$$
\left\{\begin{array}{l}
i_{A}=1.440 I_{m} \sin \left(\theta_{i}+0.883\right) \\
i_{B}=1.440 I_{m} \sin \left(\theta_{i}-1.545\right) \\
i_{C}=1.440 I_{m} \sin \left(\theta_{i}+1.798\right) \\
i_{X}=1.440 I_{m} \sin \left(\theta_{i}-0.974\right) \\
i_{Y}=1.440 I_{m} \sin \left(\theta_{i}+3.061\right)
\end{array}\right.
$$

Compared with the M1's solution, the ohmic loss increased to 1.296 times that of the M1, the maximum current is 1.44 times than in normal operation.

\section{Close LoOp CONTROL In the FAult Mode}

According to the analysis in Section II(A), in order to get the current expressed in (21), lower losses can be achieved by the harmonic subspace current $I_{\mathrm{z} 1}$ and $I_{\mathrm{z} 2}$ being set to 0 . In accordance with (11), the third harmonic voltage effects should be added. For the topology studied in this paper, $I_{z 3}$ is neglected. As a result, the close loop $\mathrm{d}-\mathrm{q}-\mathrm{Z}$ axis voltage can be expressed as (24).

$$
\begin{aligned}
\boldsymbol{u}_{\mathrm{dqz}} & =\left[\begin{array}{cccc}
P I_{d} & 0 & 0 & 0 \\
0 & P I_{q} & 0 & 0 \\
0 & 0 & P I_{z 1} & 0 \\
0 & 0 & 0 & P I_{z 2}
\end{array}\right] \times\left[\boldsymbol{i}_{d q z}^{r e f}-\boldsymbol{i}_{d q z}^{\text {real }}\right] \\
& +\omega\left[\begin{array}{cccc}
0 & -L_{q s} & 0 & 0 \\
L_{d s} & 0 & 0 & 0 \\
0 & 0 & 0 & 0 \\
0 & 0 & 0 & 0
\end{array}\right]+\omega\left[\begin{array}{c}
\Delta U_{d} \\
\Delta U_{q} \\
\Delta U_{z 1} \\
\Delta U_{z 2}
\end{array}\right]
\end{aligned}
$$

where the four parameters in the first part matrix indicate the PI regulator, which $K_{\mathrm{p}}$ is the proportional coefficient and $K_{\mathrm{i}}$ is the integral coefficient. $i_{d q z}^{r e f}$ is the reference value for PI regulator, $\boldsymbol{i}_{d q z}^{\text {real }}$ is the feedback current after the rotational transformation. $L_{\mathrm{ds}}$ and $L_{\mathrm{qs}}$ are the inductances considering the third harmonic effect. $L_{\mathrm{ds}}=L_{\mathrm{d} 1}+L_{\mathrm{m} 3}, L_{\mathrm{qs}}=L_{\mathrm{q} 1}+L_{\mathrm{m} 3}, \Delta U$ are the compensation voltages for the output voltages in each subspace. For M1 method, the compensation voltage is shown in (25).
TABLE I

SP-PMSG PARAMETERS

\begin{tabular}{|l|l|}
\hline Resistor & $1.4 \Omega$ \\
Main inductance & $2.04 \mathrm{mH}$ \\
Leakage inductance & $1.76 \mathrm{mH}$ \\
Number of pole-pairs & 2 \\
Magnet flux & $0.68 \mathrm{~Wb}$ \\
Inertia & $0.015 \mathrm{kgm}^{2}$ \\
Slot & 36 \\
\hline
\end{tabular}

$$
\left\{\begin{array}{l}
\Delta U_{d}=0.3 \omega \psi_{m 3}(\cos 2 \theta-\cos 4 \theta-\sin 2 \theta+\sin 4 \theta) \\
\Delta U_{q}=0.3 \omega \psi_{m 3}(\cos 2 \theta+\cos 4 \theta+\sin 2 \theta+\sin 4 \theta) \\
\Delta U_{z 1}=0 \\
\Delta U_{z 2}=2 \omega \psi_{m 3}(\cos 3 \theta-\sin 3 \theta)
\end{array}\right.
$$

For the M2 method, the ohmic losses increased indicating that the harmonic currents were injected into the z1-z3 subspace. The injected harmonic currents cannot be gained in the optimization process, while they can be calculated by applying $\boldsymbol{T}(\theta)$ to the optimization results. The reference currents in the harmonic subspace were calculated as shown in (26).

$$
\left\{\begin{array}{l}
i_{z 1}^{r e f}=0.2953 i_{q}^{r e f} \sin \theta-0.7542 i_{q}^{r e f} \cos \theta \\
i_{z 2}^{r e f}=0.4176 i_{q}^{r e f} \sin \theta+0.0505 i_{q}^{r e f} \cos \theta \\
i_{z 3}^{r e f}=0
\end{array}\right.
$$

The voltage expression of M2 is same as the M1 method, the compensation voltage in (25) also fits for the M2 method because the harmonic inductance and flux were not influenced by the current.

\section{Simulations RESUlT}

The parameters of the SP-PMSG utilized in this paper are listed in Table I.

To achieve an ideal Matlab model the fundamental current was taken into account in the simulation only. Therefore, the simulation results cannot reflects the third harmonic effects. All of them validate the correctness of the theory referred to in Section III.

The two versions of optimization presented in Section III were validated. The parameters used in the simulations and experiments are shown in Table I. All of the simulations have been performed at $150 \mathrm{rpm}$ and $7 \mathrm{~N} . \mathrm{m}$. In this paper, in order to compare the currents intuitive, all of the currents are expressed in magnitude. If the RMS value is needed, it can be gained by dividing by $\sqrt{2}$. Fig. 2 presents the stator currents operating in the normal condition. The currents in the XYZ windings shift 30 degree from the $\mathrm{ABC}$ winding, and the torque of the SP-PMSG operates in 7 N.m steadily with lower ripples that can be neglect . 


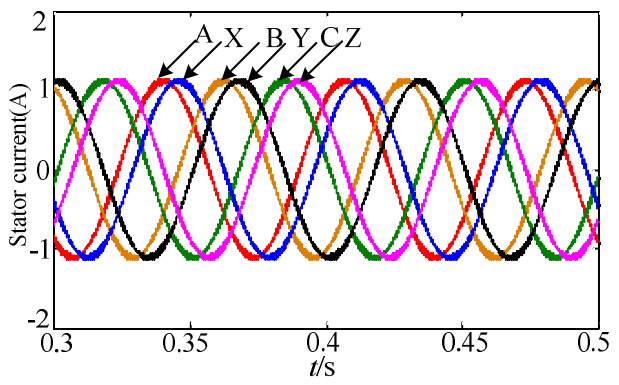

(a)

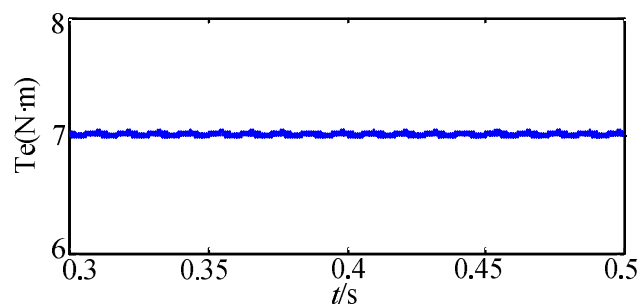

(b)

Fig. 2. Stator current and torque in normal operation ((a)stator current,(b) electromagnetic torque )

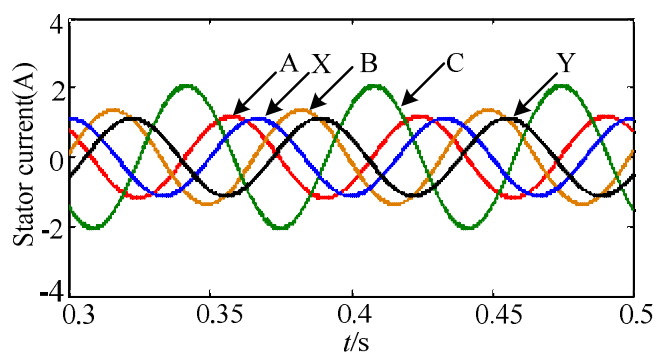

(a)
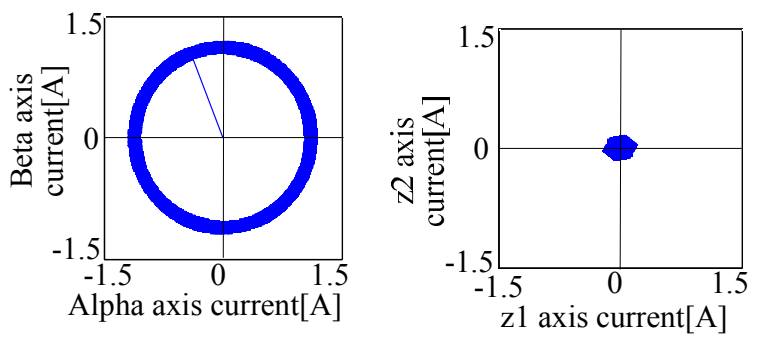

(b)

Fig. 3. Fault tolerant control with M1 method ((a) currents, (b) current in $\alpha-\beta$ subspace and in $z 1-z 2$ subspace ).

Fig. 3(a) indicates the SP-PMSG under the fault tolerant control in the M1 method. Even though each phase current never has the same magnitude, the $\mathrm{C}$ phase current reached $2.05 \mathrm{~A}$, while the $\mathrm{X}$ and $\mathrm{Y}$ phase currents are the lowest at $1.11 \mathrm{~A}$ which the same as in normal operation. In addition, each phase current is sinusoidal. Fig.3(b) and Fig.4(b) show the currents in the $\alpha-\beta$ subspace and in the $z 1-z 2$ subspace with both methods. It also indicates that the MMF recovers to normal operation. The difference is that the currents in the $z 1-z 2$ subspace with M1 is lower than M2 but not equal to 0. Fig.4(a) shows that the SP-PMSG with the M2 method is controlled

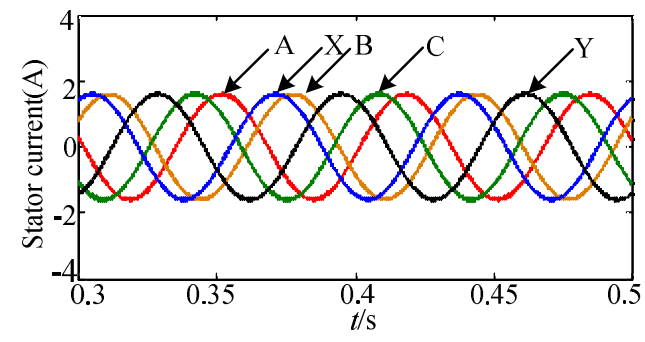

(a)
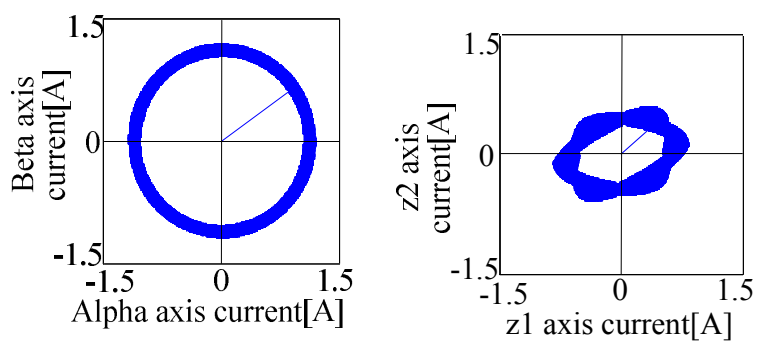

(b)

Fig. 4. Fault tolerant control with M2 method ((a) currents, (d) current in $\alpha-\beta$ subspace and in $z 1-z 2$ subspace).

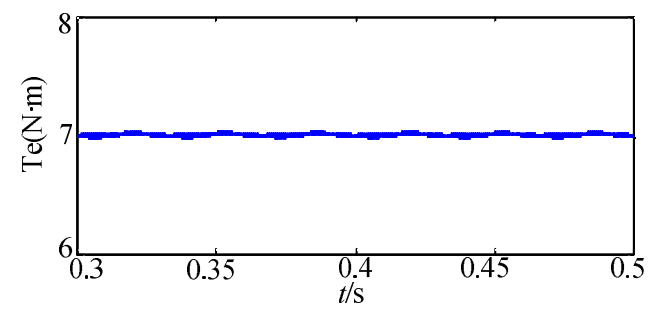

Fig. 5. Electromagnetic torque under fault tolerant control.

when the $\mathrm{Z}$ phase is open. All of the phase currents magnitudes are $1.60 \mathrm{~A}$ equally and sinusoidal well. Fig. 5 shows that the torque recovers to $7 \mathrm{~N} . \mathrm{m}$ under both of the fault tolerant controls. It is as smooth as in the normal condition.

\section{EXPERIMENTAL RESULTS}

To verify the efficiency of the proposed method, an experimental test-rig bed has been developed. The test rig is shown in Fig.6. The switching frequency is set to $12.5 \mathrm{kHz}$ using the classical SPWM technique. The control algorithm was validated on a TC1767 digital signal controller manufactured by the Infineon company. The CPU receives the stator current data by its 12-bit A/D converter. All of the PWM output was produced by a general purpose time array (GPTA). The speed was measured through a resolver and decoder by AD2S1200.

Several experiments have been carried out on the test-rig. Firstly, it must be noted that there are no filters between the converter and the PMSG. Therefore, the harmonics will be more than with filters. All of the waveforms were measured by a YOKOGAWA DLM2024 oscilloscope, and the power was measured by a WT1806. The SP-PMSG operates at $150 \mathrm{rpm}$, and the DC motor output power is equal in each 


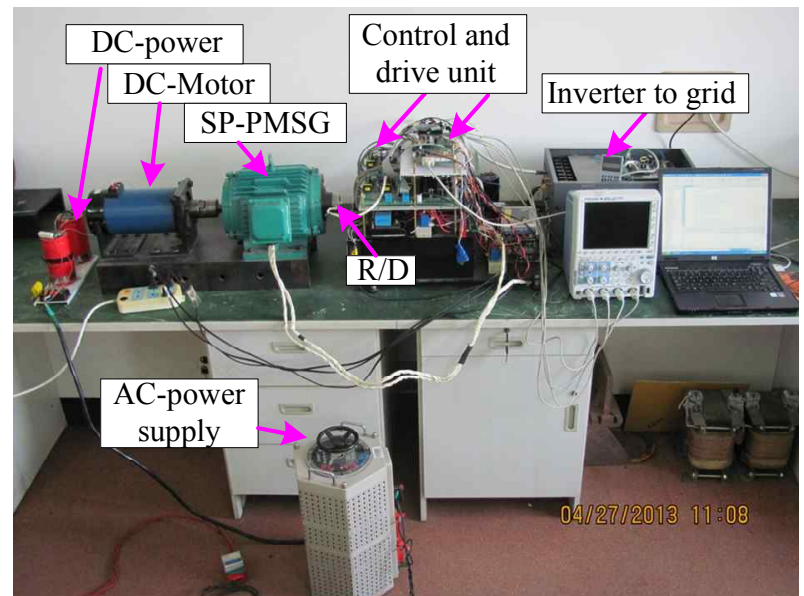

Fig. 6. SP-PMSG experimental test rig.

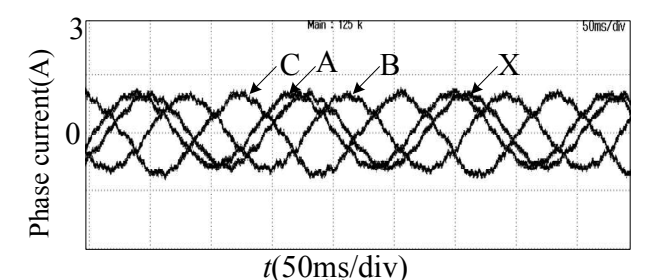

(a)

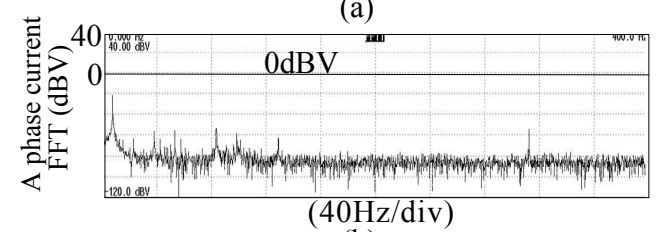

(b)

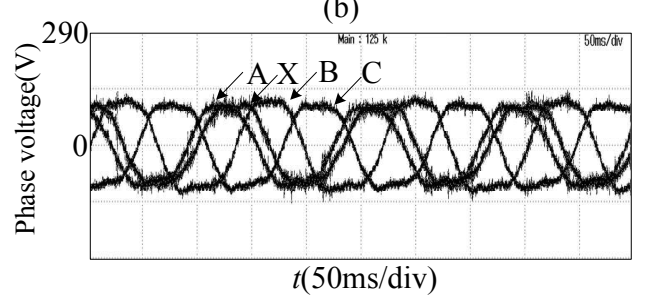

(c)

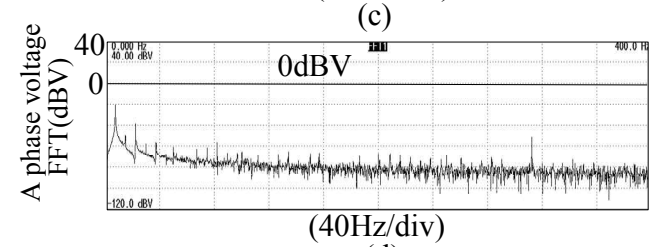

(d)

Fig. 7. SP-PMSG operates in normal state with vector space decomposition((a) stator currents, (b) A phase current FFT analysis, (c) phase voltages, (d) A phase voltage FFT analysis ).

occasion. Since no torque and speed transducers were used in the test rig, the speed was output by a D/A board. The speed fluctuation reflects the torque ripples, so no torque experiments were involved.

\section{A. Experimental Results of the Normal States}

Fig. 7(a) presents the current under normal conditions with the SVPWM modulation, where the magnitudes are 1A, and $\mathrm{X}$ phase shifts 30 degree from A phase. Fig. 7(b) presents the

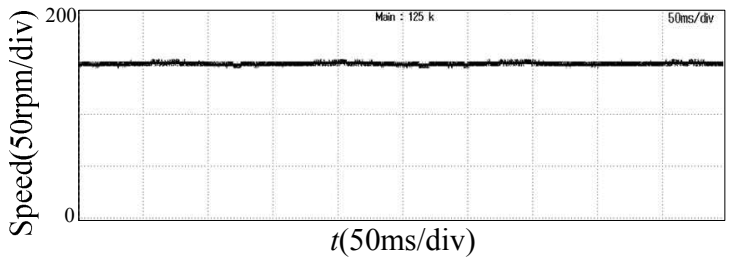

(a)
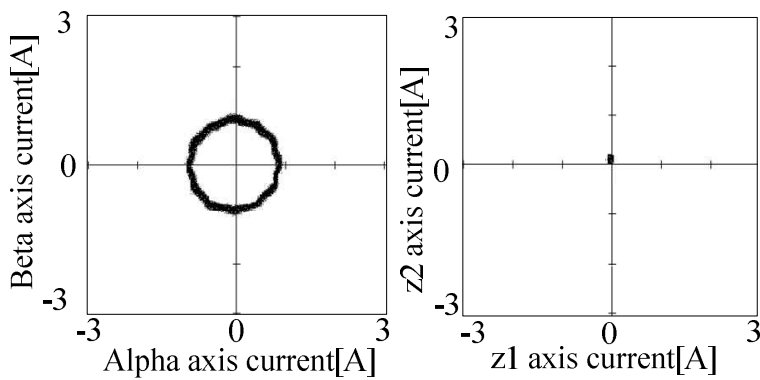

(b)

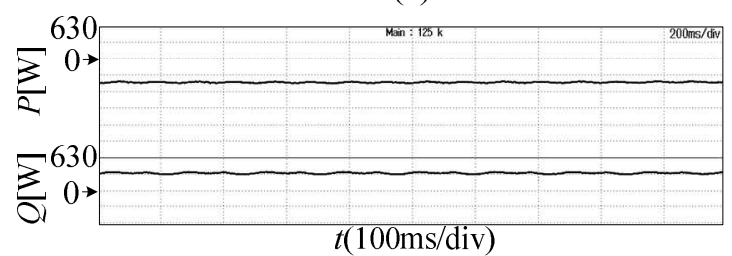

(c)

Fig. 8. The performance of SP-PMSG operates in normal state ((a) Speed, (b) currents in alpha-beta subspace and in $z 1-z 2$ subspace), (c) active power and reactive power.

A phase currents and their FFT analysis. The 3rd, 5th, and 7th harmonics were less contained in the currents, since there are essentially $6 N \pm 1$ harmonic in a six phase motor. As a result, the 11th and 13th harmonics are slightly higher, but their effects can be neglected. The voltage of the steady states are distributes normally, and it contains third and fifth harmonics.

When in steady state, the SP-PMSG operates smoothly in terms of speed and at $150 \mathrm{rpm}$ steadily. In addition, ripples are hardly seen, as shown in Fig.8(a). As shown in Fig.8(b), the currents in the alpha-beta subspace indicate that the MMF is well distributed in the air gap. At the same time, the currents in the $z 1-z 2$ subspace indicate harmonics which were not involved energy conversion. As can be seen, the harmonics losses are very low in the $z 1-z 2$ subspace in the steady state. Fig.8(c) shows that the active power fluctuates slightly, and that the reactive power is at a very low level.

\section{B. Experimental Results of the Fault States}

Fig. 9(a) shows the SP-PMSG operating in the fault state with SVPWM and no fault tolerant control. The currents are not equal and evenly distributed. The magnitude of the $\mathrm{C}$ phase current reaches $2.4 \mathrm{~A}$, and the currents have more harmonic such as the 3th, 5th, 7th, 9th, 11th, and 13th, as shown in Fig. 9(b). Similarly, the phase voltage is distributed as shown in Fig. 9(c). In addition, the magnitude is not equal as normal, and it contains various harmonics such as 2 nd, 


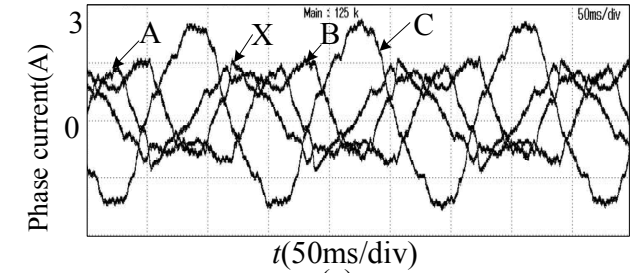

(a)

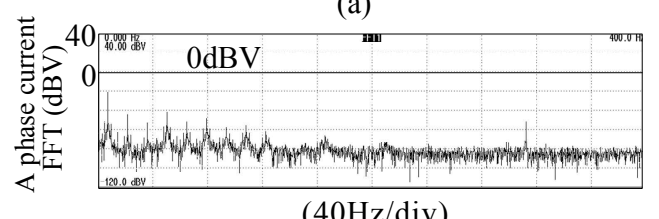

(b)

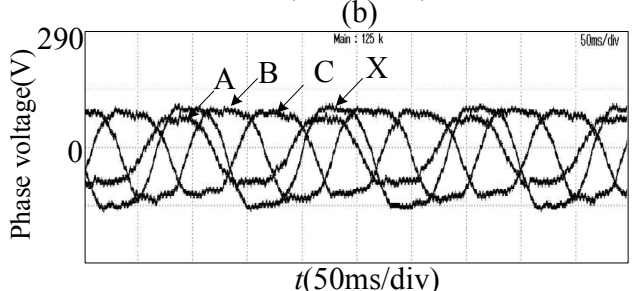

(c)

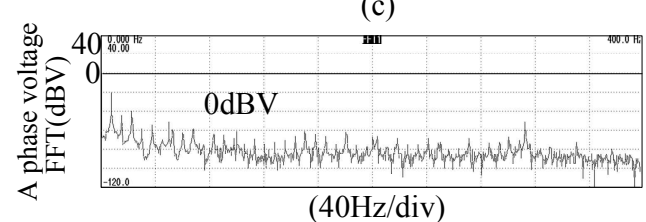

(d)

Fig. 9. Six phase PMSG operates in fault state with vector space decomposition and without fault tolerant control ((a) stator currents, (b) A phase current FFT analysis, (c) phase voltages, (d) A phase voltage FFT analysis).

3rd, 4th, 5th, 7th, etc.

For the deteriorated voltage and currents, the performance of the SP-PMSG is in the faulty state, as shown in Fig.10. By applying the stationary transformation matrix of the normal state for the currents, the currents in the $\alpha$ axis and $\beta$ axis were no longer had a phase shift of 90 degrees. The harmonics were also transformed in the $z 1-z 2$ subspace. As a result, the distortion of the currents caused $I_{\alpha}-I_{\beta}$ to be elliptical and contain harmonics, and the currents in the harmonic subspace obviously increase, as shown in Fig.10(b). This leads to twice the torque ripples and speed fluctuations, as shown in Fig.10(a). Fig.10(c) shows that active power fluctuates irregularly, and that the reactive power increased a lot more.

\section{Fault Tolerant Control in the M1 Method}

Following the strategy proposed in section III, the M1 method was applied to improve the performance of the SP-PMSG in the faulty state. By applying the transformation matrix (5) and (6) for the fault currents, as shown in Fig.11, the SP-PMSG currents and voltages under the M1 strategy are controlled without compensation and called M1A. The magnitude of the currents are obviously reduced, and the

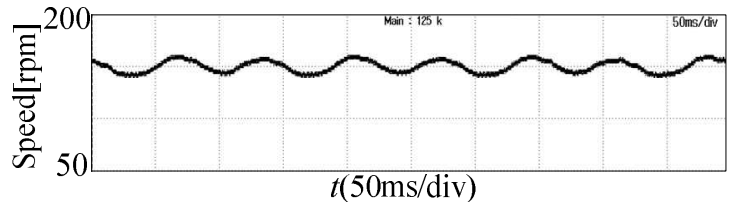

(a)
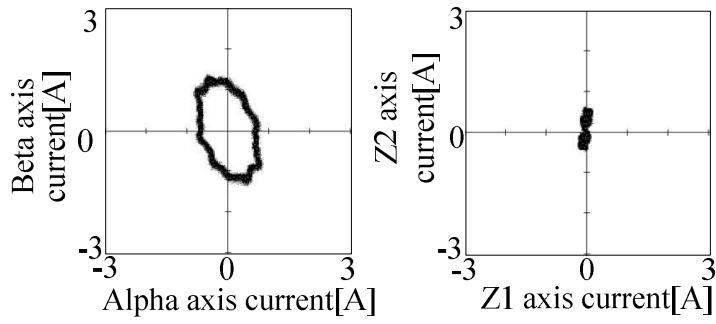

(b)

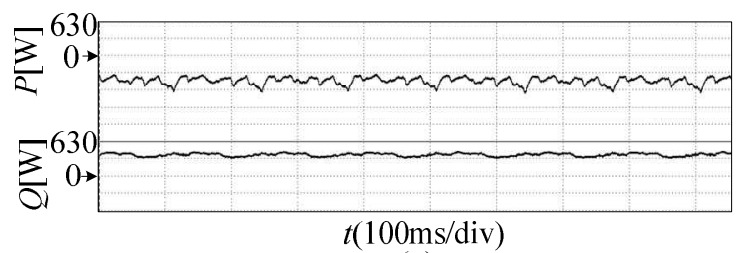

(c)

Fig. 10. The performance of SP-PMSG operates in faulty state ((a) Speed, (b) currents in alpha-beta subspace and in $z 1-z 2$ subspace), (c) active power and reactive power).

currents are not sinusoidal and obviously have the 3rd harmonic as shown in the A phase current FFT. The voltage can be distributed as the normal state and it contain less harmonics when compared to Fig.9(d). It can be seen that the 2nd, 4th, 5th, and 7th harmonics are dramatically reduced. The SP-PMSG speed recovered to $150 \mathrm{rpm}$ steadily. Due to currents with higher 3rd harmonic, Fig.12(b) presents the $I_{\alpha}-I_{\beta}$ and $I_{z 1}-I_{z 2}$ variety law, which indicates the MMF irregular distribution. even though the reference was set to zero, the current in the $z 2$ subspace has much higher feedback currents which cannot meet the ohmic loss minimum requirement. The results suggested that only the speed or torque of the SP-PMSG under the M1 strategy without compensation recover to smooth operation. Fig12(c) shows that the active power and reactive power fluctuate as the faulty state. Therefore, it can be deduced that the severe harmonic losses in the harmonic subspace cause active fluctuations with a higher magnitude.

This drawback is overcome after compensation under the M1 method, and this method was called M1B. It can be clearly seen that the currents coincide to the theoretical analysis and the simulation results. Currents with lower harmonics are shown in Fig.13(b). The 3rd harmonic was obviously reduced, and 7th also dropped to a low level. For the compensation voltage function, the harmonics of the voltage with compensation in the M1method are much higher than those without compensation, as can be seen in Fig.13(d). Fig. 14(a) shows that speed performance can achieved the 


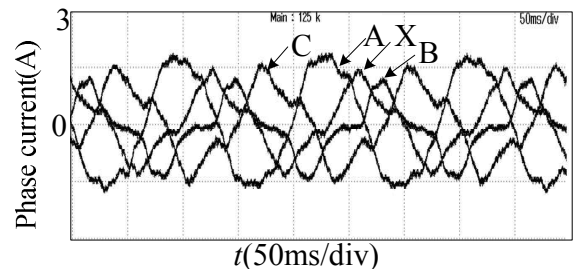

(a)

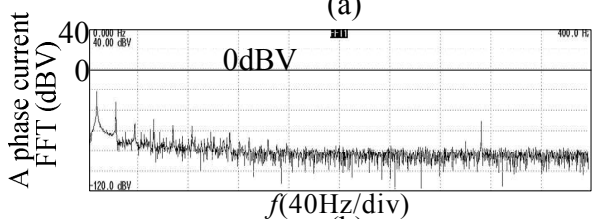

(b)

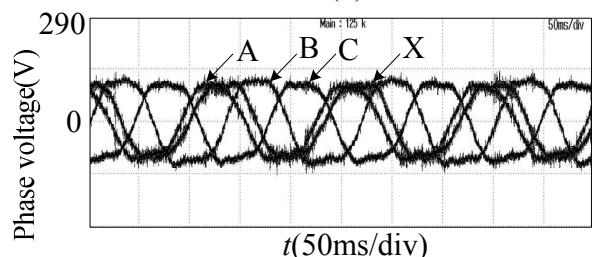

(c)

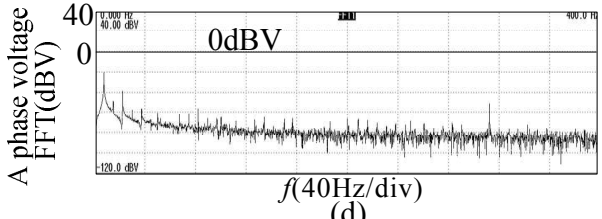

(d)

Fig. 11. Six phase PMSG operates in fault tolerant control with M1 method without harmonic compensation((a) stator currents, (b) A phase current FFT analysis, (c) phase voltages, (d) A phase voltage FFT analysis).

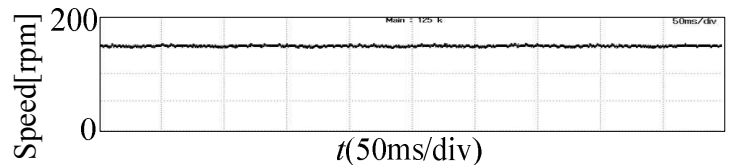

(a)
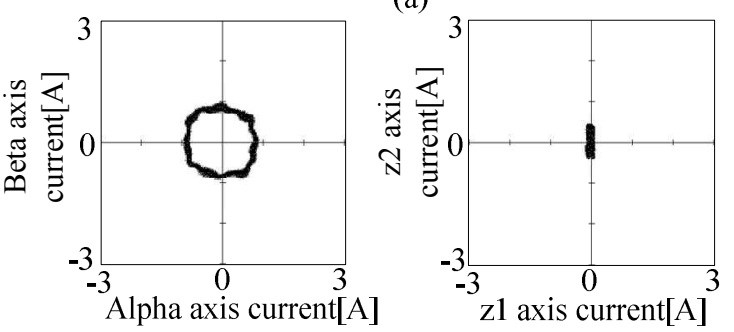

(b)

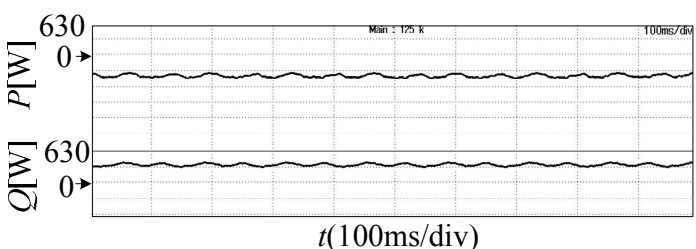

(c)

Fig. 12. The performance of SP-PMSG operates in M1 method without compensation ((a) Speed, (b) currents in alpha-beta subspace and in $z 1-z 2$ subspace), (c) active power and reactive power).

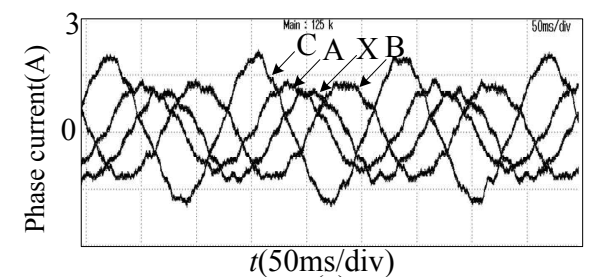

(a)

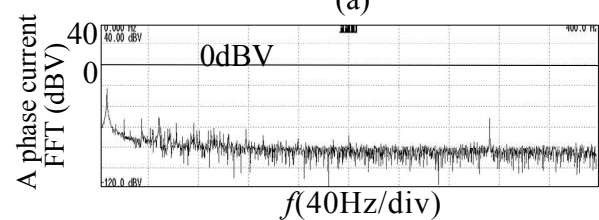

(b)

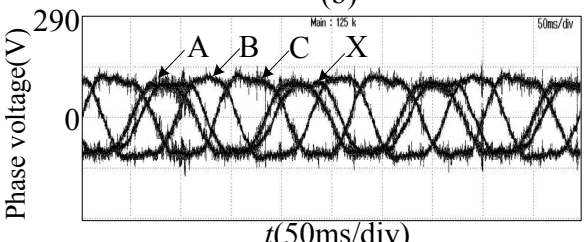

(c)

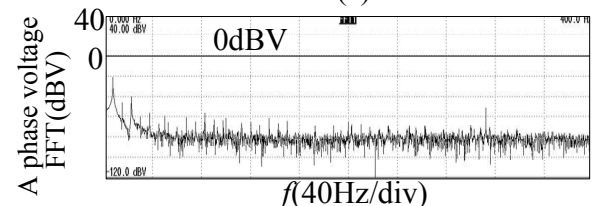

(d)

Fig. 13. Six phase PMSG operates in fault tolerant control with M1 method with harmonic compensation((a) stator currents, (b) A phase current FFT analysis, (c) phase voltages, (d) A phase voltage FFT analysis).

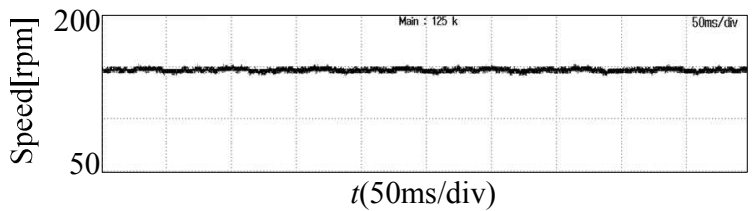

(a)

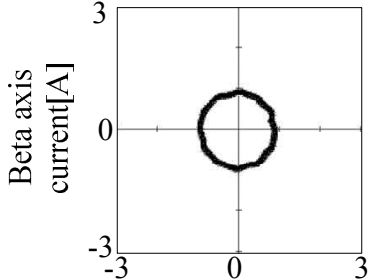

Alpha axis current $[\mathrm{A}]$

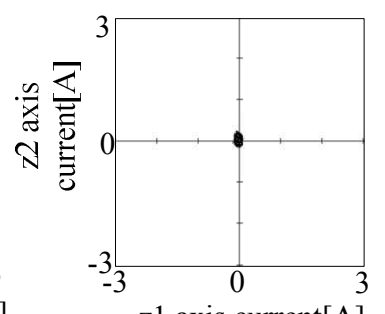

(b)

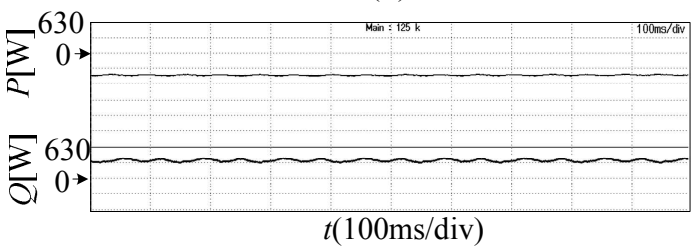

(c)

Fig. 14. The performance of SP-PMSG operates in M1 method with compensation((a) Speed, (b) currents in alpha-beta subspace and in $z 1-z 2$ subspace), (c) active power and reactive power). 
normal state steadily. The most obvious improvement is that the current in the $z 2$ subspace is decreased to a very low level. This means the ohmic loss dropped, and the efficiency increased.

\section{Fault Tolerant Control in the M2 Method}

Fig. 15 presents the SP-PMSG under the M2 strategy control without compensation (M2A). Due to the third harmonic flux and inductance effects, the requirements of the M2 strategy are hard to achieve so that the magnitudes of each of the phase currents are equal. The currents contain more harmonics than the M1 method for the currents injected to the $z 1-\mathrm{z} 2$ subspace. There is no obvious difference in the voltage comparison for the M1 method.

The performance of the SP-PMSG is presented in Fig. 16, for injection to the harmonic subspace. Although the speed of the SP-PMSG operates at 150rpm steadily, Fig. 16(b) shows that the MMF is similar to Fig. 12(b) with M1 method. This means that the third harmonic effect causes MMF with ripples. When $I_{z 1}-I_{z 2}$ increase to a much higher level, it means that the ohmic loss will be a lot higher than normal state. Fig. 16(c) shows that the harmonic losses in the $z 1-z 2$ subspace causes the active power to fluctuate violently.

When compared to Fig. 15, Fig. 17 presents the results with voltage compensation under the M2 strategy (M2B). The phase magnitudes of the $\mathrm{A}, \mathrm{B}, \mathrm{C}, \mathrm{X}$ phase currents are very close, which corresponds to the theoretical and simulation results. After compensation, the 3rd harmonics in the currents decrease to $-86 \mathrm{dBV}$ compared to Fig. 15(b) at $-74 \mathrm{dBV}$. All of the fault tolerant control strategies are based on the MMF balance principle. As a result, the fault tolerant voltage in each strategy has no obvious difference. This can be seen in Fig. 7(b), Fig. 11(b), Fig. 13(b), Fig. 15(b), and Fig. 17(b).

Fig. 18(a) presents the SP-PMSG operating at 150rpm without violent ripples. In Fig. 18(b), $I_{\alpha}-I_{\beta}$ shows that the MMF recovers to the normal state and distributes evenly in the air gap. At the same time, the elliptical trace of $I_{z 1}-I_{z 2}$ is identical to that of the theoretical analysis. After voltage compensation, the active power outputs smoothly and the reactive power with lower twice ripple are shown in Fig. 18(c). However, the reactive power has little effect on the system steady operation.

As the power dates in Table II indicate, the efficiency of the SP-PMSG is not highly efficient when it operates in a light load. However, it should be noted that the output power of the M2 methods are less than both of the M1 methods. Due to the currents injection to the $z 1-z 2$ subspace, the active power contains much more ohmic loss $P_{\text {loss. }}$. The efficiency of M1B is the highest. After compensation, it can be seen that the efficiency of both methods were raised.

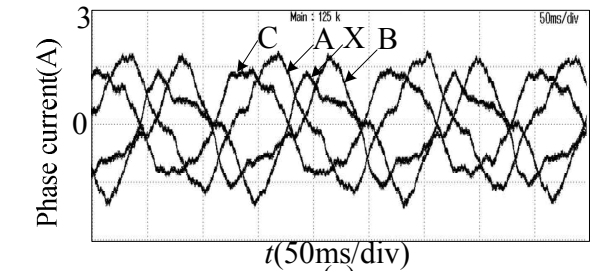

(a)

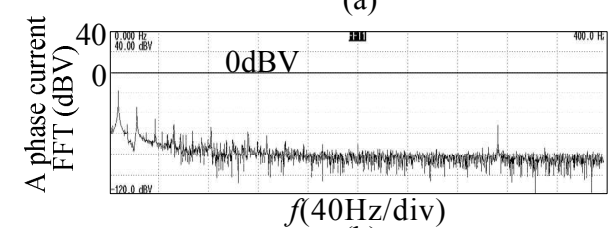

(b)

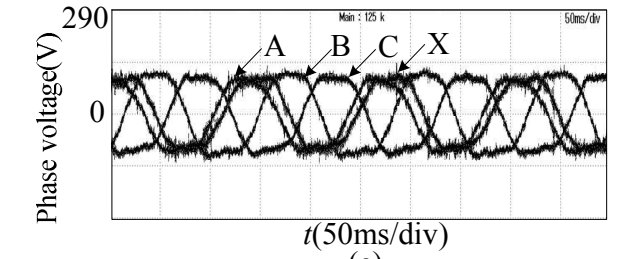

(c)

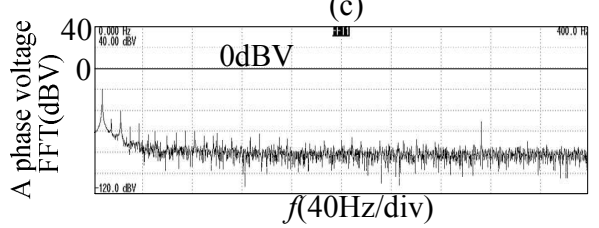

(d)

Fig. 15. Six phase PMSG operates in fault tolerant control with M2 method without harmonic compensation((a) stator currents, (b) A phase current FFT analysis, (c) phase voltages, (d) A phase voltage FFT analysis).

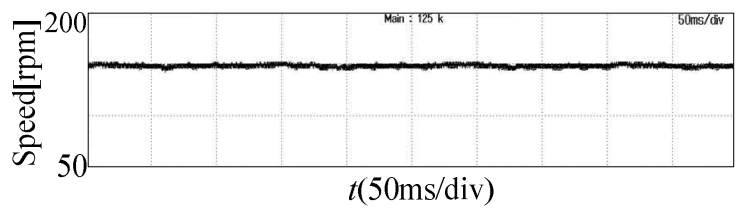

(a)
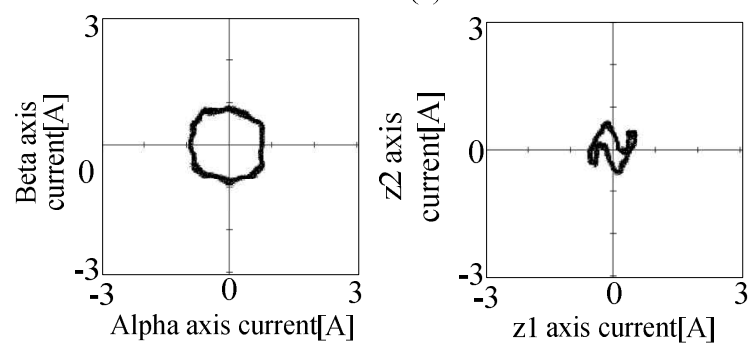

(b)

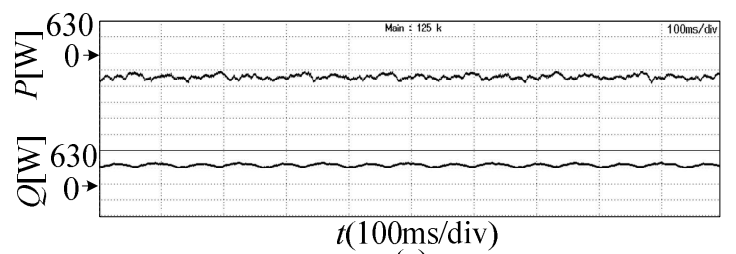

(c)

Fig. 16. The performance of SP-PMSG operates in M2 method without compensation((a) Speed, (b) currents in alpha-beta subspace and in $z 1-z 2$ subspace), (c) active power and reactive power). 


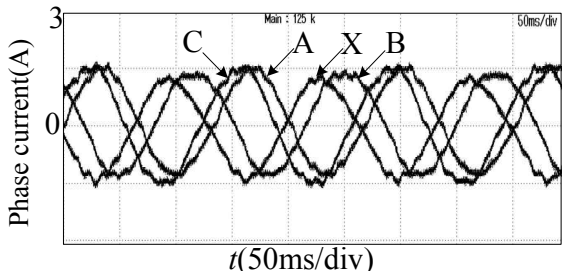

(a)

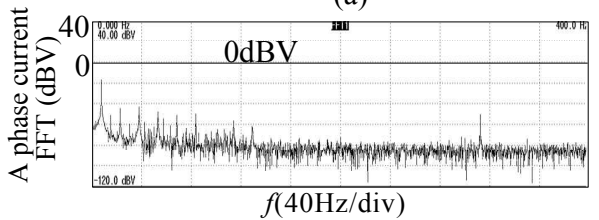

(b)

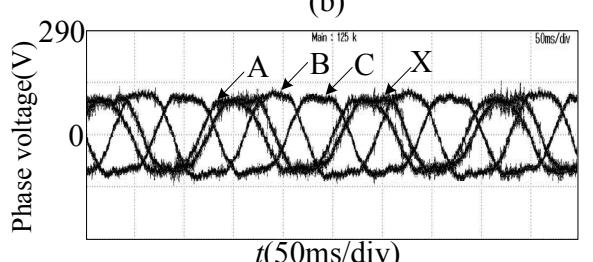

(c)

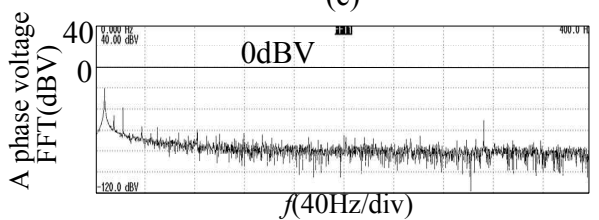

(d)

Fig. 17. Six phase PMSG operates in fault tolerant control with M2 method with compensation((a) stator currents, (b) A phase current FFT analysis, (c) phase voltages, (d) A phase voltage FFT analysis).

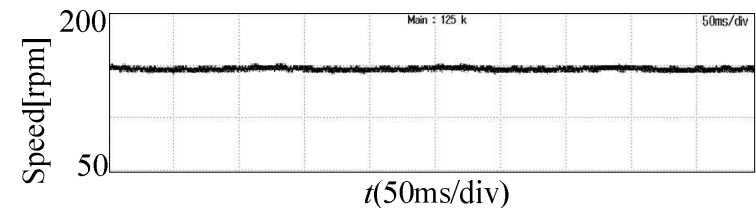

(a)
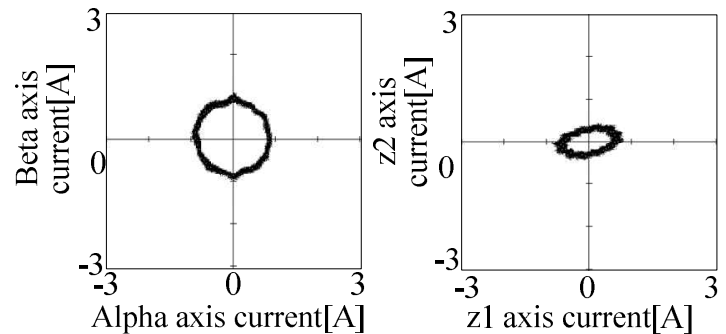

(b)

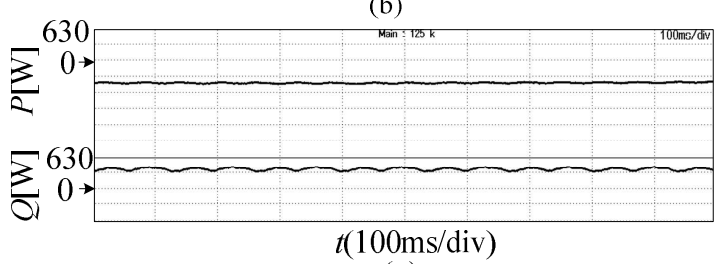

(c)

Fig. 18. The performance of SP-PMSG operates in M2 method with compensation((a) Speed, (b) currents in alpha-beta subspace and in z1-z2 subspace), (c) active power and reactive power).
TABLE II

POWER OUTPUT AND EFFICIENCY

\begin{tabular}{ccccc}
\hline & M1A & M1B & M2A & M2B \\
\hline $\boldsymbol{P}$ & 414 & 429 & 408 & 420 \\
$\boldsymbol{Q}$ & 366 & 344 & 370 & 359 \\
Efficiency & 0.75 & 0.78 & 0.74 & 0.76 \\
\hline
\end{tabular}

\section{CONCLUSIONS}

This paper proposes a model of a SP-PMSG under the fault of a one phase open circuit while considering the third harmonic effect. By analyzing the third harmonic flux and inductance effects for the torque and voltage, a voltage compensation method was proposed with the strategies of stator ohmic loss minimum and stator currents magnitude minimum. Even though the analytic solutions of the fault tolerant fundamental currents can be gained by extending the transformation matrix, for the coupling effect of the fundamental and third harmonic, the twice torque ripple is hard to eliminate. The extended transformation matrix takes the effects for the fundamental and the third harmonics. After transformation, the twice, third, and fourth ripples were introduced to the torque and the electromechanical energy conversion subspaces, to eliminate the harmonic inductance and flux effects. The unique compensation voltage was added to the current loop output according to the motor's parameters. As a result, the compensation magnitude can be calculated offline. For multi-phase permanent magnet synchronous motors, if the extended transformation matrix is established, the compensation magnitude can be specified according to the different strategy requirements. A comparison of the experimental results suggested that the proposed method can eliminate the third harmonic effects and improve the power efficiency of SP-PMSGs.

\section{ACKNOWLEDGMENT}

This work was supported by National Key Basic Research Program of China under Grant 2013CB035605 and National Natural Science Foundation of China (51177026).

\section{REFERENCES}

[1] E. Levi, R. Bojoi, F. Profumo, H. A. Toliyat, and S. Williamson, "Multiphase induction motor drives-a technology status review," IET Trans. Electric Power Application, Vol. 1, No. 4, pp.489-516, Jul. 2007.

[2] F. Baudart, B. Dehez, E. Matagne, D. Telteu-Nedelcu, P. Alexandre, and F. Labrique, "Torque control strategy of polyphase permanent-magnet synchronous machine with minimal controller reconfiguration under open-circuit fault of one phase," IEEE Trans. Ind. Electron., Vol. 59, No .6, pp. 2632-2644, Jun 2012.

[3] D. Vizireanu, S. Brisset, X. Kestelyn, P. Brocheta, Y. Milet, and D. Laloyc "Investigation on multi-star structures for large power direct-drive wind generator," Electric Power Components and Systems, Vol. 35, No. 2, pp. 135-152, Feb. 2007. 
[4] C. B. Jacobina, R. S. Miranda, M. B. D. R. Correa, and A. M. N. Lima, "Disturbance free operation of a six-phase AC motor drive system," in Proceeding of IEEE_PESC, pp. 925-931, 2004.

[5] Y. F. Zhao and T. A. Lipo, "Modeling and control of multi-phase induction machine with structural unbalance: part 1," IEEE Tran. Energy Convers., Vol. 11, No. 3, pp. 570-577, Sep. 1996.

[6] J. Prieto, F. Barrero, M. Jones, and E. Levi, "A modified continuous PWM technique for asymmetrical six-phase induction machines," in IEEE ICIT, pp. 1489-1494, 2010.

[7] W. U. N. Fenando, M. Barnes, and O. Marjanovic, "Direct drive permanent magnet generator fed AC-DC active rectification and control for more electric aircraft engines," IET Trans. Electric Power Applications, Vol. 5, No. 1, pp. 14-27, Jan. 2011.

[8] M. J. Duran, S. Kouro, B. Wu, E. Levi, F. Barrero, and S. Alepuz, "Six-phase PMSG wind energy conversion system based on medium-voltage multilevel converter," in Proceeding of EPE2011, pp. 1-10, Birmingham, Aug. 2011.

[9] H. A. Toliyat, "Analysis and simulation of five-phase variable-speed induction motor drives under asymmetrical connections," IEEE Trans. Power Electron., Vol. 13, No. 4, pp. 748-756, Jul. 1998

[10] R. Kianinezhad, B. Nahid-Mobarakeh, L. Baghli, F. Betin, and G.-A. Capolino, "Modeling and control of six-phase symmetrical induction machine under fault condition due to open phases," IEEE Trans. Ind. Electron., Vol. 55, No. 5, pp. 1966-1977, May 2008.

[11] A. Tani, M. Mengoni, L. Zarri, G. Serra, and D. Casadei, "Control of multiphase induction motors with an odd number of phases under open-circuit phase faults," IEEE Trans. Power Electron., Vol. 27, No. 2, pp. 565-577, Feb. 2012.

[12] K. Atallah, J. Wang, and D. Howe, "Torque-ripple minimization in modular permanent-magnet brushless machines," IEEE Trans. Ind. Appl., Vol. 39, No. 6, pp. 1689-1695, Nov./Dec. 2003.

[13] J. R. Fu and T. A. Lipo, "Disturbance-free operation of a multiphase current-regulated motor drive with an open phase," IEEE Trans. Ind. Appl., Vol. 30, No. 5, pp. 1267-1274, Sep. 1994.

[14] M. A. Shamsi-Nejad, B. Nahid-Mobarakeh, S. Pierfederici, and F. Meibody-Tabar, "Fault tolerant and minimum loss control of double-star synchronous machines under open phase conditions," IEEE Trans. Ind. Electron., Vol. 55, No. 5, pp. 1956-1965, May 2008.

[15] Y. F. Zhao and T. A. Lipo, "Modeling and control of a multi-phase induction machine with structural unbalance: Part 2," IEEE Trans. Energy Convers., Vol. 11, No. 3, pp. 570-577, Sep. 1996.

[16] W. U. N Fenando and M. Barnes, "Model based optimization and fault tolerant control of permanent magnet machines with harmonic injection pulse width modulation," in IEEE_VPPC, pp. 1-6, 2011.

[17] S. Dwari and L. Parsa, "Open circuit fault tolerant control of five phase permanent magnet motors with third harmonic back EMF," in 34th IECON, pp. 3114-3119, 2008.

[18] S. Dwari and L. Parsa, "Fault-tolerrant control of five-phase permanent magnet motors with trapezoidal back EMF," IEEE Trans. Ind. Appl., Vol. 58, No. 2, pp. 476-485, Feb. 2011.
[19] P. Z. Zhao, G. Yamg, and Y. Li, "Fault-tolerant control strategy for five-phase permanent magnetic synchronous motor under single phase open-circuit fault condition," Proceeding of CSEE, Vol. 31, No. 24, pp. 68-76, 2011.

[20] H. M. Ryu, J.-W. Kim, and S.-K. Sul, "Synchronous frame current control of multiphase synchronous motor under asymmetric fault condition due to open phases," IEEE Trans. Ind. Applic., Vol. 42, No. 4, pp. 1062-1070, Jul./Aug. 2006.

[21] J. M. Apsley, "Open-circuit fault mitigation for multiphase induction motors with a unified control structure," in 5 th IET Conference on PEMD, pp. 1-6, 2010.

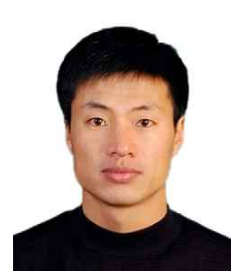

Jian Liu was born in China, in 1982. He received his B.S. degree in Electrical Engineering from the Heilongjiang Institute of Science and Technology, Harbin, China, in 2004, and his M.S. degree from the Harbin University of Science and Technology, Harbin, China, in 2009. He is currently working toward his Ph.D. degree at the Harbin Institute of Technology (HIT), Harbin, China. His current research interest include PMSM adjustable speed drives, and multi-phase motor drives and control theory.

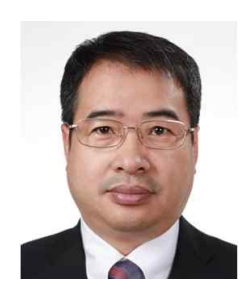

Gui-jie Yang was born in China, in 1965. $\mathrm{He}$ received his $\mathrm{Ph} . \mathrm{D}$. degree in Electrical Engineering from the Harbin Institute of Technology (HIT), Harbin, China, in 2005. Since 1992, he has been an Assistant Researcher in the Research Center of Inertial Navigation Equipment, HIT. From 1998 to 2004, he was an Associate Professor at HIT. Since 2004, he has been a Professor in the School of Electrical Engineering and Automation (SEEA), HIT. His current research interests include high power PMSG drives, integrated digital control for motors, and motor drive IP core based FPGAs.

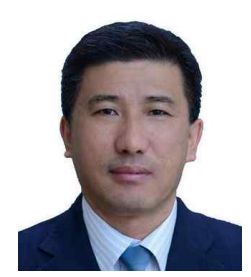

Yong Li was born in China, in 1964. He received his B.S., M.S., and Ph.D. degrees in Electrical Engineering from the Harbin Institute of Technology (HIT), Harbin, China, in 1981, 1988 and 1998, respectively. Since 2004, he has been a Professor in the School of Electrical Engineering and Automation (SEEA), HIT. His current research interests include the direct drive of BLDC designs and drives, and novel structures for PMSM principles and applications. Dr. Li serves as special reviewer for the IEEE Transactions on Magnetics.

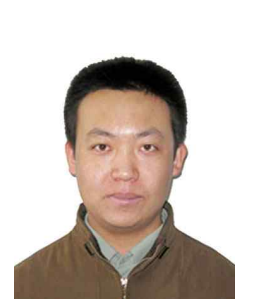

Hong-wei Gao was born in China, in 1984. $\mathrm{He}$ received his B.S. and M.S. degrees in Electrical Engineering from the Harbin University of Science and Technology, Harbin, China, in 2007 and 2011. He is currently working toward his Ph.D. degree at the Harbin Institute of Technology (HIT), Harbin, China. His current research interests include PMSM adjustable speed drives, multi-phase motor drives and control theory. 
Jian-yong Su was born in China, in 1979. He received his B.S., M.S., and Ph.D. degrees in Electrical Engineering from the Harbin Institute of Technology (HIT), Harbin, China, in 2002, 2004 and 2009, respectively. Since 2010, he has been an Assistant Researcher in the School of Electrical Engineering and Automation (SEEA), HIT. His current research interests include the slide mode control of PMSMs, high power PMSG drives and multi-phase motor control. 